\title{
A Dinâmica da avaliação escolar na construção de novos encaminhamentos metodológicos para a promoção da aprendizagem
}

\author{
Maria Aparecida Oliveira Alves ${ }^{l}$ e Edilândia Carvalho de Sousa ${ }^{2}$
}

\begin{abstract}
Resumo: A importância do ato de avaliar consiste em dialogar com o aluno sobre seu processo de aprendizagem, auxiliando-o na construção da aprendizagem satisfatória e na efetivação da melhoria da aprendizagem. O presente artigo é resultado de uma pesquisa bibliográfica integrativa da literatura. Discute a avaliação escolar como uma dinâmica que subsidia o processo de ensino-aprendizagem, no sentido de fomentar a qualidade de aprendizagem e a tomada de decisão, que direcione o aprendizado e, consequentemente, o desenvolvimento do educando. Dentre os propósitos da avaliação deve-se figurar a identificação dos obstáculos que possam comprometer a aprendizagem, identificando-se as deficiências e/ou dificuldades, num sentido de aperfeiçoamento da prática pedagógica, de modo que ajude ao desenvolvimento das capacidades e habilidades do alunado.
\end{abstract}

Palavras-chave: ensino, aprendizagem, avaliação.

\section{The dynamics of school evaluation in the construction of new methodological referrals to promoting learning.}

\begin{abstract}
The importance of the act of evaluating is to talk to students about their learning process, assisting you in the construction of satisfactory learning and improvement in the effectiveness of learning. This article is the result of an integrative literature review of the literature. Discusses the school evaluation as a dynamic that supports the process of teaching and learning in order to enhance the quality of learning and decision making, which direct the learning and hence the development of the student. Among the assessment purposes should be included identifying the obstacles that may hinder learning, identifying deficiencies and / or difficulties in the sense of improvement of pedagogical practices in order to help the development of skills and student body skills.
\end{abstract}

Keywords: teaching, learning, assessment

\section{Introdução}

O professor no exercício da atividade pedagógica constantemente está fazendo julgamento às formas de aprendizagem e ao comportamento de cada aluno seja de maneira explícita ou implícita. Considerando que todo ensino escolar parte do pressuposto de uma ação consciente através da organização dos conhecimentos sistematizados que visa orientar e estimular a aprendizagem escolar dos alunos a fim de que estes alcancem o objetivo principal da ação pedagógica - assimilação ativa dos conteúdos e o desenvolvimento das suas capacidades cognoscitivas, ou seja, que a aprendizagem seja significativa.

\footnotetext{
${ }^{1}$ Graduada em Pedagogia pela Universidade Regional do cariri - URCA; Pós-Graduada em Educação Inclusiva pela Faculdades Integradas de Patos - FIP; Especialista em Políticas Educativas e Docência do Ensino Superior pela Fac. Formação de Professores de Araripina; Mestranda em Ciências da Educação pela Universidade Lusófona de Humanidades e Tecnologias, Lisboa/PT. E-mail: aparecidaalves2011@hotmail.com

${ }^{2}$ Graduada em Letras pela Universidade Regional do Cariri -URCA. Especialista em Língua Portuguesa pela mesma universidade e Especialista em Psicopedagogia Clínica e Institucional pela Faculdades Integradas do Vale do Ivaí -UNIVALE. Mestranda em Ciências da Educação pela Universidade Lusófona de Humanidades e Tecnologias, Lisboa/PT. E-mail: edilandia1107@hotmail.com
} 
Nesse processo, a avaliação como elemento constitutivo de todo processo de ensinoaprendizagem tem por função auxiliar a construção da aprendizagem satisfatória, à medida que possibilita ao professor obter um indicador de aprendizagem que possa orientar o seu trabalho, de modo que se for necessário, ele mude seus procedimentos didáticos, favorecendo a reelaboração do ensino, tendo em vista a efetiva aprendizagem. Sobre isso, Celso Antunes apud Tavares (2011, p.108) ressalta que avalia de verdade quem pondera, quem examina o aluno e suas circunstâncias, quem, pelos caminhos dos conteúdos, aprende significações e transfere soluções, quem descobre a distância verdadeira entre o que se sabia e o que se aprendeu.

Para Tavares (2011, p. 108) nenhuma avaliação dá resultados absolutos, mas informações sobre o que e como o aluno aprendeu. E a função da avaliação é diagnosticar o processo de aprendizagem, não a capacidade do aluno.

A avaliação segundo Kenski, (2004, p. 147) só encontra sentido quando é pensada, planejada e executada tendo como objetivo auxiliar professores e/ou alunos, a aprender mais e melhor, a reorientar seus caminhos, suas formas de estudar e de lidar com os conhecimentos.

Vale lembrar que na medida em que o professor avalia como os alunos estão aprendendo e o que aprenderam, ele também esta avaliando seu ensino, assim sendo, o professor no ato de avaliar deve considerar o esforço de cada aluno de acordo com suas possibilidades, valorizar suas capacidades, habilidades e experiências, bem como, analisar, identificar e reconhecer não apenas as estratégias e dificuldades de aprendizagem do aluno, como também as inadequações em sua própria prática pedagógica.

Por isso, é extremamente relevante que o professor ao programar as ações docentes leve em consideração as situações que possa facilitar o aprender dos alunos e a retomada de estratégias e metodologias com vistas ao progresso das relações travadas no ambiente escolar, buscando sempre promover uma abertura para a pesquisa e a reflexão conectada à avaliação de modo que seja providas as condições e meios pelos quais os alunos assimilam ativamente conhecimentos, habilidades, atitudes e convicções.

\section{Metodologia}

O estudo realizado consiste em uma pesquisa bibliográfica exploratória descritiva da literatura, com abordagem qualitativa. A qual se justifica pela sua importância no processo de busca da literatura técnico, científica publicada. Para a obtenção dos dados bibliográficos foram consultados no período de junho a novembro de 2015, artigos, dissertações, livros, documentos oficiais, que versam sobre a temática avaliação escolar. 
De acordo com Lima (1997), a pesquisa bibliográfica é a atividade na qual coletamos dados gerais ou específicos a respeito de um tema, através da consulta de informações escritas em fontes diversas.

\title{
A Interdependência Entre o Planejamento e a Avaliação
}

Freire (1996) ao se referir ao modo como tem sido realizado a avaliação nas escolas, faz a seguinte crítica:

\begin{abstract}
Os sistemas de avaliação pedagógica de alunos e de professores vêm se assumindo cada vez mais como discursos verticais, de cima para baixo, mas insistindo em passar por democráticos. A questão que se coloca a nós, enquanto professores e alunos críticos e amorosos da liberdade, não é, naturalmente, ficar contra a avaliação, de resto necessária, mas resistir aos métodos silenciadores com que ela vem sendo às vezes realizada. A questão que se coloca a nós é lutar em favor da compreensão e da prática da avaliação enquanto instrumento de apreciação do que fazer de sujeitos críticos a serviço, por isso mesmo, da libertação e não da domesticação. Avaliação em que se estimule o falar a como caminho do falar com. (1996, p. 44)
\end{abstract}

Nesse sentido, Libâneo (1994, p. 203) enfatiza a relevância dos objetivos do ensino quanto à necessidade de expressarem as reais possibilidades dos alunos de modo que estejam em condições de cumprir as exigências colocadas pela escola.

Para tanto, é imprescindível que os conteúdos a serem trabalhados pelo currículo escolar estejam estreitamente relacionados com a experiência de vida dos alunos. Martins (2004, p. 83). O conteúdo só adquire significado se, vinculado à realidade existencial dos alunos, está voltado para a resolução dos problemas colocados pela prática social. Assim sendo, pode-se afirmar que o trabalho docente consiste em compatibilizar conteúdos e métodos com o nível de conhecimentos, experiências, desenvolvimento mental dos alunos (LIBÂNEO 1994, p. 43).

Nesse contexto, Caporalini (2004, p. 112) afirma:

Para a assimilação dos assuntos importa não só a quantidade como também a qualidade, que o relacionamento com a realidade vivencial do aluno é necessário, a fim de levá-lo a pensar criativamente, a resolver problemas, a manipular ideias, visando propiciar-lhe, também liberdade para explorar e experimentar e conduzi-lo à reflexão e à ação.

Nisto consiste a relevância das aulas em se constituírem em ações organizadas, práticas, que conduzem o aluno ao aprender contínuo em um processo reflexivo de constante reconstrução de conhecimentos prévios, de mudança de atitudes frente ao saber organizado que a escola lhe propicia.

(INFORSATO \& SANTOS 2011, p. 84) 
E para que a aula assim se constitua, antes é preciso entender que o planejamento deve corresponder:

\begin{abstract}
A um processo de racionalização, organização e coordenação da ação docente, articulando a atividade escolar e a problemática do contexto social. [...] o planejamento é uma atividade de reflexão acerca das nossas opções e ações; se não pensarmos detidamente sobre o rumo que devemos dar ao nosso trabalho ficaremos entregues aos rumos estabelecidos pelos interesses dominantes na sociedade. A ação de planejar, portanto, não se reduz ao simples preenchimento de formulários para controle administrativo; é antes, a atividade consciente de previsão das ações docentes, fundamentadas em opções político-pedagógicas, e tendo como referência permanente as situações didáticas concretas (isto é, a problemática social, econômica, política e cultural que envolve a escola, os professores, os alunos, os pais, a comunidade, que interagem no processo de ensino) (LIBÂNEO 1994, p. 222)
\end{abstract}

Em vista disso, os conteúdos precisarão estar relacionados com a experiência de vida dos alunos, às suas condições mentais e físicas para uma assimilação ativa, suas condições prévias para a aprendizagem e principalmente, que esteja estritamente vinculado com as relações entre a escola e a realidade histórico-social.

Percebe-se que o planejamento corresponde a uma atividade que exige competência técnicopedagógica, isto é, exige que o professor domine conteúdos e metodologia e saiba adequar os conteúdos às condições de aprendizagem dos alunos. (SOUZA 2008, p.154).

É importante aprender aquilo que se ensina na escola, portanto, é preciso então que todas as atividades sejam discutidas, planejadas, executadas e sirvam de impulso para novas realizações, conforme propaga Freire (1996, p. 12) ensinar não é transferir conhecimento, mas criar as possibilidades para a sua produção ou a sua construção.

Nesse intuito, deve-se, considerar os conhecimentos que são significativos para a formação do educando, priorizando tanto os conteúdos, quanto as formas de apresentação e de avaliação dos saberes, portanto, ao realizar o planejamento é necessário que o professor conheça a realidade na qual ele vai trabalhar, conheça e considere as experiências que os alunos já trazem, seus interesses e necessidades, bem como, quais suas expectativas em relação ao ensino e a função da escola enquanto instituição que tem como uma de suas tarefas segundo Feldmann $(2009$, p. 80) a formação de pessoas com pensamento autônomo, que sejam fieis aos seus sonhos, respeitem a pluralidade e a diversidade e intervenham de forma científica e crítica nos destinos da sociedade.

Logo, os conhecimentos escolares já não podem ser vistos como mera adaptação dos conhecimentos científicos, tampouco serem tomados como verdades definitivas e fechadas a serem apresentadas aos alunos para serem assimiladas (NADAL 2009, p. 30). E assim como os conhecimentos escolares não devem ser apresentados de forma estática e como verdades acabadas, é a avaliação.

Para Libâneo (1994, p. 190) a avaliação é processo sistemático e contínuo, no decurso do qual vão sendo obtidas informações e manifestações a cerca do desenvolvimento das atividades 
docentes e discentes. E conclui que esta é uma reflexão sobre o nível de qualidade do trabalho escolar tanto do professor quanto do aluno.

Assim sendo, a avaliação deve auxiliar ao professor a entender o processo de elaboração de conhecimento dos alunos e a pensar na relação pedagógica, pois, embora a avaliação seja uma das etapas de um plano de ensino, ela é também a precursora de novos planejamentos, pois, conforme os seus resultados o professor define e redefine novos objetivos, novas metodologias e até mesmo novos instrumentos e critérios das avaliações, ou seja, a avaliação pode redimensionar toda a prática pedagógica indicando novos rumos, novos caminhos a ser tomados no ensino permitindo, o (re)planejamento das aulas e a elaboração de novas atividades e de novas avaliações.

Zabala (1999, p. 17) apud, Pimenta \& Lima (2004, p.183) destaca a relação existente entre o planejamento e a avaliação:

O planejamento e a avaliação dos processos educacionais são uma parte inseparável da atuação docente, já que o que acontece nas aulas, a própria intervenção pedagógica, nunca pode ser entendida sem uma análise que leve em conta as intenções, as previsões, as expectativas e a avaliação dos resultados.

Nesse contexto a avaliação pode ser definida como um instrumento de compreensão do estágio de aprendizagem em que se encontra o aluno, que visa tomar decisões suficientes e satisfatórias para que este possa avançar no seu processo de aprendizagem, para isso, os resultados são comparados com os objetivos propostos, a fim de constatar progressos, dificuldades, e reorientar o trabalho para as correções necessárias. (LIBÂNEO 1994, p. 195) (LUCKESI 2008, p. $81)$.

\title{
Os Processos da Avaliação da Aprendizagem no Contexto Escolar.
}

Para Santos (2011, p. 106) o processo de avaliação tem inicio quando:

\begin{abstract}
São levantados os conhecimentos prévios dos alunos. A partir disso é possível estabelecer objetivos e metas, escolher conteúdos e aplicar métodos. Tendo um ponto de partida, a avaliação torna-se auxiliadora, quantitativamente e principalmente qualitativamente, do processo de ensino-aprendizagem em que progresso ou fracasso são importantes para se repensar as estratégias com vistas a auxiliar o desenvolvimento do aluno.
\end{abstract}

Nessa perspectiva, faz-se necessário que avaliação considere tanto o conhecimento prévio e o nível atual de desenvolvimento do aluno quanto às possibilidades de aprendizagem futura, não se restrinja a apenas à atribuição de notas, visando à promoção ou reprovação do aluno, mas que consistir numa dinâmica que de fato orienta a prática, levando em consideração a relação mútua entre os aspectos quantitativos e qualitativos. 
A relevância da verificação prévia dos conhecimentos do aluno consiste em possibilitar o avanço ou retroceder nos planejamentos, a avaliação começa bem antes, no início da interação didática, e prossegue durante todo o processo de aprendizagem. É um processo contínuo e formativo, diagnóstico que orienta novos encaminhamentos para o processo de ensino e de aprendizagem.

No entendimento de Libâneo (1994) a avaliação é uma tarefa complexa que não se resume à realização de provas e atribuição de notas. O autor afirma ainda que a avaliação escolar cumpre pelo menos três funções que atuam de forma interdependente, não podendo ser consideradas isoladamente: pedagógico-didáticas, de diagnóstico e de controle:

\begin{abstract}
A função pedagógico-didática está referida aos próprios objetivos do processo de ensino e diretamente vinculada às funções de diagnóstico e de controle. A função diagnóstica se torna esvaziada se não estiver referida à função pedagógico-didática e se não for suprida de dados e alimentada pelo acompanhamento do processo de ensino que ocorre na função de controle. A função de controle, sem a função de diagnóstico e sem o seu significado pedagógico-didático, fica restringida à simples tarefa de atribuição de notas e classificação. (1994, p.198)
\end{abstract}

O referido autor enfatiza que, a função diagnóstica se destaca como meio de propiciar aos alunos o controle da sua própria atividade, uma vez que são participantes ativos e sujeitos do processo de aprendizagem. (LIBÂNEO 1994, p.190). O momento de avaliar é também para diagnosticar dificuldades e mostrar caminhos de superação. (ANDRADE 2014, p. 21).

Gonçalves \& Larchert, (2011, p. 88) declaram que se a prática pedagógica for fundamentada nos princípios de transformação, inclusão e emancipação, a avaliação tende a ser transformadora, construtiva e passa a se caracterizar como diagnóstica, processual e contínua. Nesse contexto, a avaliação da aprendizagem é definida por Luckesi (2008, p. 172) como um ato amoroso, no sentido de que a avaliação, por si, é um ato acolhedor, integrativo, inclusivo.

Assim sendo, a avaliar os alunos representa incluí-la no mundo do conhecimento. Assim caracteriza-se o tipo de avaliação que é preparada para ensinar, reforçar o processo de aprendizagem, e não apenas para atribuir notas, medindo o que foi memorizado (ANDRADE 2014, p. 21).

No entanto, Veiga (2004, p. 48) faz uma crítica em relação às formas como a avaliação tem sido vivenciada dentro das escolas, de acordo com autora:

Ela é, ainda, de cunho classificatório, autoritário, punitivo e excludente. Dessa ótica, a avaliação exerce a função de controle social por reforçar as divisões sociais inerentes à sociedade capitalista. A avaliação é vista como responsável pela marginalização dos indivíduos, ao exclui-los do sistema escolar, seja impedindo sua entrada, seja impedindo seu avanço. Nesse sentido ela não permeia o PPP da escola, pois está vinculada quase exclusivamente ao desempenho do aluno. 
Estas formas de avaliação tornam sem efeito a principal função do ato de avaliar, ou seja, impossibilita que esta auxilie a tomada de decisão do professor em prol da melhoria da aprendizagem. Avaliações assim estão totalmente desvinculadas dos valores da sociedade, grupo social e contexto histórico em que se realiza, portanto, a escola precisa e mais precisamente o professor ter mais criatividade, compromisso e competência para realiza-las de modo mais justo e mais democrático, conforme deve ser.

Nessa perspectiva, a Lei de Diretrizes e Bases - LDB - (LEI nº-9394/96) em seu artigo 24, estabelece que a avaliação do desempenho do aluno deve ser contínua e cumulativa prevalecendo os aspectos qualitativos sobre os quantitativos e dos resultados ao longo do período sobre os de eventuais provas finais.

\section{Formação Docente: Pré-Requisito Para um Ensino de Qualidade}

A escola tem por finalidade garantir a educação de uma sociedade, assegurando que os direitos e saberes por ela proferidos se perpetuem através das gerações (FELDMANN \& D’ÁGUA 2009, p. 190).

Nesse sentido, Freire ressalta:

Uma das tarefas essenciais da escola, como centro de produção sistemática de conhecimento, é trabalhar criticamente inteligibilidade das coisas e dos fatos e a sua comunicabilidade. É imprescindível, portanto, que a escola instigue constantemente a curiosidade do educando em vez de "amaciá-la" ou "domesticá-la". (1996, p.46)

Em vista disso, cabe ao professor realizar de modo sistemático, as ligações do conteúdo proposto no currículo escolar com a dimensão social que o aluno possui, relacionando com a experiência dos mesmos. Uma vez que qualquer assunto a ser desenvolvido em sala de aula já estar presente na prática social, como parte constitutiva dela. (GASPARIN 2007, p. 23-24) (LOPES 2004, p. 58).

\footnotetext{
$\mathrm{O}$ que se busca com um trabalho educacional contextualizado e voltado para a comunidade é integrar o aluno com o mundo em que vive, levando-o a conhecer criticamente o ambiente natural e social que o cerca, reconhecendo o seu mundo e pensando sobre ele, valorizando sua realidade através de uma postura exploratória, reflexiva e crítica. (Almeida, 2002, p. 73).
}

Para tanto, o planejamento segundo Libâneo (1994, p. 226) deve considerar os objetivos e tarefas da escola democrática; as exigências dos planos e programas oficiais; as condições prévias dos alunos para a aprendizagem; os princípios e as condições do processo de transmissão ativa dos conteúdos que são os principais requisitos para o planejamento conforme enfatiza. Nesse contexto, planejar consiste numa ação consciente pela qual o indivíduo concebe uma coisa futura e motivado 
pelo desejo e vontade, se esforça pela sua realização, implica definições claras sobre o que fazer, para quê? Como e para quem. (SOUZA 2008, p.152).

De acordo com Libâneo (1994) a linha fundamental de compreensão do processo didático é a unidade objetivo-conteúdo-métodos:

\begin{abstract}
Os objetivos, explicitando propósitos pedagógicos intencionais e planejados de instrução e educação dos alunos, para participação na vida social; os conteúdos constituem a base informativa concreta para alcançar os objetivos e determinar os métodos; os métodos formam a totalidade dos passos, formas didáticas e meios organizativos do ensino que viabilizam a assimilação dos conteúdos e, assim, o atingimento dos objetivos. (LIBÂNEO 1994, p. 154-155).
\end{abstract}

Nesse processo exige-se do professor novas competências no sentido de uma maior profissionalização, com a autonomia e a responsabilidade que a acompanham; uma ênfase na prática reflexiva, uma cooperação profissional (PERRENOUD 2005, p.154)

Para Feldmann (2009, p. 71) o Professor é um sujeito que professa saberes, valores, atitudes, que compartilha relações e, junto com o outro, elabora a interpretação e reiterpretação do mundo. Nesse contexto, o professor no desempenho de sua função precisa orientar-se na busca pela unidade da teoria e prática, ou seja, da práxis, é importante que o professor reflita sobre sua prática, pois, sua prática deve ser compreendida e trabalhada numa perspectiva de constante reflexão sobre a natureza do ser professor e os aspectos que permeiam a identidade docente.

Um dos fundamentos da formação docente instituído pela LDB (artigo 61 inciso I) é a associação entre teorias e praticas, mediante a capacitação em serviço, contudo, na prática percebe-se que há um certo distanciamento entre os cursos de formação e o exercício da profissão de professor.

Nesse contexto, acredita-se que para melhorar a formação docente faz-se necessária uma revisão profunda dos diferentes aspectos que interferem na formação inicial de professores, tais como: a organização institucional, a definição e estruturação dos conteúdos para que respondam às necessidades da atuação do professor, os processos formativos que envolvem aprendizagem e desenvolvimento das competências do professor a vinculação entre as escolas de formação inicial e os sistemas de ensino.

Quanto à formação continuada de professores segundo Silva (2007, p.100) deve incentivar a sua apropriação do saber rumo à autonomia, e levar a uma prática crítico-reflexiva, abrangendo a vida cotidiana da escola e o saber derivado da experiência docente. Silva acrescenta ainda que o objetivo da formação continuada é:

Principalmente, desenvolver o pensamento reflexivo, o formador dever apresentar, ou sistematizar com os professores em formação, problemas que exijam solução reflexiva. Dessa forma, o problema tem que possuir valor funcional, partindo de contextos problemáticos reais, concretos e significativos; ser motivador e desafiador; e ser formulado de maneira clara e precisa. (2007, p.105) 
É preciso implementação de políticas de formação profissional e de valorização do magistério, tendo em vista que sem investimento na formação dos profissionais da educação não se conquistará as metas de qualidade que vem se tornando cada vez mais consensuais.

Nesse sentido, Freitas (2007) ressalta:

A formação dos professores não pode estar desarticulada de uma política de melhoria da qualidade do ensino. A meta de que os alunos possam ser sujeitos da sua própria formação implica construir um objetivo idêntico para o processo de formação dos professores, uma vez que o educador só pode dar sua tarefa por realizada quando ele coloca seu trabalho a serviço da aprendizagem de todos os alunos. Desse modo, o alvo da formação precisa ser o de construir e consolidar caminhos que permitam a conquista, pelo professor, de autonomia nas dimensões social e pedagógica. (2007, p. 14-15).

As atividades desenvolvidas na ação pedagógica segundo Pimenta \& Lima:

Têm por finalidades a efetivação do ensino da aprendizagem por parte dos professores e alunos. Este processo de ensino e aprendizagem é composto de conteúdos educativos, habilidades e posturas científicas, sociais, afetivas, humanas; enfim, utiliza-se de mediações pedagógicas específicas. (2004, p. 42)

Sobre a atuação docente onde acontece a intervenção pedagógica Zabala (1999, p. 17) apud, Pimenta \& Lima (2004, p.183) afirma que o planejamento e a avaliação dos processos educacionais são uma parte inseparável, portanto, a intervenção pedagógica, nunca pode ser entendida sem uma análise que leve em conta as intenções, as previsões, as expectativas e a avaliação dos resultados. Inexiste validade no ensino de que não resulta um aprendizado em que o aprendiz não se tornou capaz de recriar ou de refazer o ensinado, em que o ensinado que não foi apreendido não pode ser realmente aprendido pelo aprendiz. (FREIRE 1996, p. 13)

O ensino não existe por si mesmo, mas na relação com a aprendizagem a qual consiste na assimilação ativa de conhecimentos e de operações mentais, para compreendê-los e aplica-los consciente e autonomamente (LIBÂNEO 1994, p. 91).

Ao falar sobre a pedagogia contemporânea Roza (2008) ressalta:

A pedagogia contemporânea entende que o processo de construção do conhecimento remete à aprendizagem, a uma educação que visa à formação intelectual e cidadã do sujeito, efetivando-se no espaço pedagógico através de processos interativos de reflexão, de discussão e de permanentes questionamentos, de promoção de situações que permitam ao acadêmico mobilizar seus conhecimentos, ressignificá-los e contextualizá-los frente aos novos conhecimentos. (2008, p. 26)

Ensinar e aprender são instrumentos de luta, portanto torna-se imperativo ter uma conduta ética, articulada com os interesses da maioria e, acima de tudo, dispor-se, ser competente para tornar efetiva a função social da escola plenamente. (SILVA 2002, p. 42). 


\section{Considerações Finais}

A avaliação é elemento constitutivo de todo processo de ensino aprendizagem, portanto, deve está sempre a serviço da aprendizagem e não simplesmente para verificar se houve ou não aprendizagem, assim sendo, o plano de ensino do professor deve ser pensado com base nos objetivos do ensino e no conhecimento da realidade social, definindo os meios eficientes para se obter os resultados, de modo que esteja comprometido com as finalidades sociais e políticas.

Nesse sentido, vale ressaltar a importância e necessidade de o professor criar situações estimuladoras para provocar no aluno, reações ou respostas que garantam a formação de atitudes intelectuais e sentimentais adequadas, para o domínio dos conhecimentos sistematizados, habilidades e hábitos para que, por meio deles, desenvolvam suas capacidades mentais. De modo que os alunos não aprendem somente o que desejam, mas que se apropriem do que é socialmente relevante para formação dos cidadãos de hoje.

O professor ao avaliar o que o aluno aprendeu, deve-se ter em mente quais serão suas ações diante dos resultados obtidos, pois, ao verificar o nível de aprendizagem em que este se encontra, o professor está também avaliando sua prática pedagógica, nesse processo ele atribui um juízo de valor ao que o aluno aprendeu, independente de qual seja esse valor, exige-se uma tomada de decisão do professor no sentido de saber o que será feito com resultados obtidos.

A grande importância do ato de avaliar consiste na consciência de quem avalia em saber que a prática da avaliação sempre deve repercutir positivamente no processo de ensino aprendizagem, o que não quer dizer que as notas ou conceitos atribuídos ao educando deve ser os mais altos ou melhores, mas no sentido de que os resultados da avaliação constitui-se o ponto de partida para a adoção de novos métodos, novas direções, novos caminhos a serem percorridos visando em todo o tempo a superação das dificuldades enfrentadas pelo o aprendiz no seu processo de aquisição de conhecimento de modo que este continue aprendendo.

A avaliação não deve se resumir ao mero instrumento de aprovação ou reprovação do aluno, mas sim, num momento dialético do processo de desenvolvimento de novas competências levando ao crescimento e a autonomia do educando.

Para cumprir sua verdadeira função a avaliação precisa ser objetiva, contínua, comprometida e coerente com os objetivos do ensino, com a necessidade de aprendizado do aluno e compatível e com seu nível de desenvolvimento, ou seja, com a zona de desenvolvimento proximal do aluno, refletindo a unidade objetivos-conteúdos-métodos, delineados no plano de ensino.

Para o desempenho de avaliações nesse sentido, faz-se necessário que o professor tenha uma formação fundamentada em um trabalho de reflexibilidade crítica sobre as práticas e de reconstrução permanente de uma identidade pessoal profissional, de maneira que estes sejam capazes de desenvolver um processo de ensino que possibilita ao aluno aprender de forma criativa, 
dinâmica, encorajadora tendo como essência o diálogo e a descoberta, de maneira significativa e transformadora, sendo avaliado através de uma avaliação que estar a serviço da aprendizagem que cada vez mais lhe inclui e não exclui do direito de aprender.

\section{Referências}

ALMEIDA, Ana Maria Bezerra de. Interação escola / comunidade: ampliando o campo de estágio. IN: ALMEIDA, Ana Maria Bezerra de. [et al]; ALMEIDA, Ana Maria Bezerra de. LIMA, Maria Socorro Lucena. SILVA, Silvina Pimentel. Dialogando com a escola: reflexões do estágio e ação docente nos cursos de formação de professores Fortaleza. Edições Demócrito Rocha, 2002.

ANDRADE, Fabiana. A pedagogia do afeto na sala de aula. $2^{\mathrm{a}}$ ed. Recife editora: Prazer de Ler, 2014.

CAPORALINI, Maria Bernadete Santa Cecilia. Na dinâmica interna da sala de aula: o livro didático. IN: VEIGA, Ilma Passos Alencastro (coord.) Repensando a Didática. $21^{\mathrm{a}}$ ed. Revisada, e atual - Campinas SP, Papirus, 2004.

FELDMANN, Maria Graziela. Formação de professores e cotidiano escolar. IN: FELDMANN, Maria Graziela, (org.). Formação de professores e escola na contemporaneidade. São Paulo: Editora Senac, 2009.

FELDMANN, Maria Graziela. D’ÁGUA, Solange vera Nunes de Lima. Escola e inclusão social: relato de uma experiência. IN: FELDMANN, Maria Graziela, (org.). Formação de professores e escola na contemporaneidade. São Paulo: Editora Senac, 2009.

FREIRE, Paulo. Pedagogia da autonomia: Saberes necessários à prática educa tiva. São Paulo. Paz e Terra, 1996. - (Coleção Leitura). $25^{a}$ edição.

FREITAS, Alexandre Simão de. Os desafios da formação de professores no século XXI: competências e solidariedade. IN: FERREIRA, Tereza Brito. ALBUQUERQUE, Eliana Borges Correia de. LEAL, Telma Ferraz. (orgs.) Formação continuada de professores: questões para reflexão. 1 ed., 2 reimp. Belo Horizonte. Autêntica , 2007. Disponível em <https://pt.scribd.com/.../FORMACAO-CONTINUADA-DE-PROFESSOR...> acesso em 29/agost/ 2015.

GASPARIN, João Luiz. Uma Didática para a Pedagogia Histórico-Crítica. $4^{\mathrm{a}}$ edição revista e ampliada - Campinas - São Paulo - editora: Autores Associados, 2007. - (coleção educação contemporânea)

GONÇALVES, Alba Lúcia. LARCHERT, Jeanes Martins Ilhéus. Avaliação da aprendizagem. volume 6 - EAD. Universidade Estadual de Santa Cruz - UESC (Ilhéus -BA) 2012. Disponível em: nead.uesc.br/...aprendizagem/modulo-avaliacao-aprendizagem.pdf acesso em 09.jun. 2015

KENSKI, Vani Moreira. Repesando a avaliação da aprendizagem. IN: VEIGA, Ilma Passos Alencastro (coord.) Repensando a Didática. 21 a ed. Revisada, e atual - Campinas SP, Papirus, 2004.

Lei De Diretrizes E Bases Da Educação Nacional. 6a edição-atualizada em 2007 
LIBÂNEO, José Carlos. Didática. (Coleção Magistério. $2^{\circ}$ grau. Série formação do professor). São Paulo. Cortez, 1994.

LIMA, Manolita Correia. A Engenharia da Produção Acadêmica. São Paulo: Unidas, 1997.

LOPES, Antonia Osima. Planejamento do ensino numa perspectiva crítica de educação. IN: VEIGA, Ilma Passos Alencastro (coord.) Repensando a Didática. $21^{\text {a }}$ ed. Revisada, e atual Campinas SP, Papirus, 2004.

LUCKESI, Carlos Cipriano. Avaliação aprendizagem escolar: estudos e proposições 19 ed. São Paulo, Cortez, 2008.

MARTINS, Pura Lúcia Oliver. Conteúdos escolares: a quem compete a seleção e a organização? IN: VEIGA, Ilma Passos Alencastro (coord.) Repensando a Didática. $21^{\mathrm{a}}$ ed. Revisada, e atual - Campinas SP, Papirus, 2004.

NADAL, Beatriz Gomes. A escola e sua função social; uma compreensão à luz do projeto de modernidade. IN: FELDMANN, Maria Graziela, (org.). Formação de professores e escola na contemporaneidade. São Paulo: Editora Senac, 2009.

PERRENOUD, Philippe. Escola e Cidadania: o papel da escola na formação para a democracia. (trad. Fátima Murad). Porto Alegre: Artmed, 2005.

PIMENTA, Sena Garrido. LIMA, Maria Socorro Lucena. Estágio e Docência. São Paulo: Cortez, 2004 - (coleção docência em formação. Série Saberes Pedagógicos).

ROZA, Jacira Pinto da. Desafios da Docência: algumas reflexões sobre a possibilidade de uma gestão pedagógica da pesquisa. IN: KRONBAUER, Selenir Corrêa Gonçalves. SIMIONATO, Margareth Fadanelli (orgs.). Formação de professores: abordagens contemporâneas. São Paulo, Paulinas, 2008.

SANTOS, Robson Alves. Avaliação: instrumento de desenvolvimento pedagógico. IN: UNIVERSIDADE ESTADUAL PAULISTA. Prograd. Caderno de Formação: formação de professores didática geral. São Paulo: Cultura Acadêmica, 2011. Disponível em <www.acervodigital.unesp.br/bitstream/.../Caderno de Formacao D15.pd...> Acesso em $05 /$ set $/ 2015$.

INFORSATO, Edson do Carmo. SANTOS, Robson Alves dos. A preparação das aulas. IN: UNIVERSIDADE ESTADUAL PAULISTA. Prograd. Caderno de Formação: formação de professores didática geral. São Paulo: Cultura Acadêmica, 2011. Disponível em www.acervodigital.unesp.br/bitstream/.../Caderno_de_Formacao_D15.pd... Acesso em $17 /$ jun/2015.

SILVA, Silvina Pimentel. A função social da escola. IN: ALMEIDA, Ana Maria Bezerra de. [et al]; ALMEIDA, Ana Maria Bezerra de. LIMA, Maria Socorro Lucena. SILVA, Silvina Pimentel. Dialogando com a escola: reflexões do estágio e ação docente nos cursos de formação de professores Fortaleza. Edições Demócrito Rocha, 2002.

SILVA, Everson Melquiades Araújo. Dispositivos metodológicos para a formação continuada de professores: uma abordagem crítico-reflexiva. IN: IN: FERREIRA, Tereza Brito.

ALBUQUERQUE, Eliana Borges Correia de. LEAL, Telma Ferraz. (orgs.). Formação continuada de professores: questões para reflexão. 1 ed., 2 reimp. Belo Horizonte. Autêntica, 2007. 
Disponível em 〈https://pt.scribd.com/.../FORMACAO-CONTINUADA-DE-PROFESSOR... > acesso em 29/agost/ 2015.

SOUZA, Rosa Fátima de. Escola e currículo. Curitiba: IESDE Brasil S.A, 2008, 176 p.

Disponível em https://books.google.com.br/books?isbn=8538706020

TAVARES, Rosilene Horta. Didática Geral. Belo Horizonte. Editora Universidade Federal de Minas Gerais - UFMG, 2011.

Disponível em www.mat.ufmg.br/ead/acervo/livros/Didatica\%20Geral.pdf acesso em 20/jul/2015.

VEIGA, Ilma Passos Alencastro. Didática: uma retrospectiva histórica. IN: VEIGA, Ilma Passos Alencastro (coord.) Repensando a Didática. 21 a ed. Revisada, e atual - Campinas SP, Papirus, 2004.

\section{Como citar este artigo (Formato ABNT):}

ALVES, M.A.O.; SOUSA, E.C. A dinâmica da avaliação escolar na construção de novos encaminhamentos metodológicos para a promoção da aprendizagem. Id on Line Revista de Psicologia, November de 2015, vol.9, n.28. p. 119-131. ISSN 1981-1189.

Recebido: 18/08/2015

Aceito:15/09/2015 